\title{
LA CULTURA Y LAS POLÍTICAS DE REHABILITACIÓN Y VALORIZACIÓN DE LOS CENTROS HISTÓRICOS
}

\author{
Francisco Pol Méndez (Arquitecto - Profesor asociado DUyOT)
}

\section{1.}

Lo que se nos pide: esbozar en un par de páginas lo que consideremos la aportación más importante de la reflexión y las prácticas de la urbanística en los últimos cincuenta años. iAhí es nada! Pero no es tan mal formato. Más difícil lo tenía Julian Barnes, para mí el más interesante escritor británico de ese arco de tiempo, cuando tituló una de sus mejores obras, compuesta de breves relatos, Historia del mundo en diez capítulos y medio... Desde mi perspectiva: la conformación de la cultura y las políticas de recuperación de los centros históricos en la primera mitad de los 70 en Italia, Francia y otros países europeos, que se extendería a España a principios de los 80 , y se desarrollaría hasta hoy, influenciando, a través de "ampliaciones de campo" y de "incorporaciones de temas", buena parte de los planteamientos y prácticas urbanísticas recientes (valorización de los paisajes urbanos, regeneración de barrios, diseño de nuevos crecimientos desde reelaboraciones actuales de los modelos de la ciudad clásica europea etc.)

Esa conformación se produjo a través de procesos complejos -de algún modo similares a los que dieron lugar, en anteriores etapas, a otros cambios de paradigmas culturales- mediante dinámicas e inesperadas agregaciones, intersecciones, adentramientos y confluencias de muy diversas líneas de pensamiento y de elaboraciones propositivas, con un campo de referencia material y a la vez ideal e "ideado", la ciudad antigua ... En el escenario de todos esos procesos concurrieron muy diversos "malestares": la desazón de las corrientes más vivaces y críticas de la cultura urbanística ante los resultados de los nuevos crecimientos orientados por la vulgata de las doctrinas funcionalistas (las informes "periferias de masas", y no las prometidas cités radieuses). Las indagaciones de sociólogos, geógrafos, psicólogos urbanos... pero también de "observadores/activistas", sobre las erosiones y escisiones que en la vida social generaban esos esquemas de crecimiento. La paulatina germinación en la cultura arquitectónica de atenciones hacia la "inserción" en la historia, en buena parte asentadas en la apreciación de la "segunda tradición" del Movimiento Moderno... Más otros aspectos, derivados de inesperados acontecimientos económicos y de cambios de climas políticos y sociales: las nuevas sensibilidades y comportamientos derivados del mayo 68, las inquietudes y reflexiones inducidas por la brusca crisis económica de 1973, provocada por la desmesurada alza de los costes del petróleo, que generaron nuevas actitudes sobre los "límites del crecimiento" y los "equilibrios ambientales", abriendo crecientes debates que, con otras muchas aportaciones, configurarían la actual cultura de la sostenibilidad. Más los impactos políticos y sociales provocados por el reconocimiento de los extensos y graves problemas de deterioro y de habitabilidad de la edificación antigua (en algunos países, como Francia y Reino Unido, como resultado de surveys específicos, en España como resultado de estudios sobre ciudades concretas). Más la difusión proteica de movimientos sociales y luchas vecinales en oposición a operaciones de renovación 
urbana con objetivos especulativos, en defensa del patrimonio histórico, en reivindicación de medidas para la mejora de las condiciones de vivienda...

Todas esas atenciones e intenciones, de contornos difusos, encontraron un "campo de condensación" en la idea de salvaguardia y recuperación de los centros antiguos como modelo de una nueva cultura y de la política de la ciudad: otorgando así un inesperado protagonismo a unos ámbitos hasta entonces casi marginales en las políticas públicas y en el pensamiento urbanístico dominante. En efecto, como es bien sabido, en las ideologías del planeamiento funcionalista, codificadas institucionalmente, esos tejidos habían sido considerados como rémoras de unos pasados urbanos "ineficientes", "desajustados", "insalubres", y por tanto como objetos de necesarias reformas, de alcance a veces extremo, más allá de la casi rutinaria aceptación de la preservación de los grandes episodios monumentales. Las corrientes que reivindicaban la conservación de los cascos antiguos, por sus valores propios o contextuales, que se expresaron en la Carta de Atenas de 1939 (curiosamente simultánea a la alentada por Le Corbusier y otras personalidades de los CIAM como cuadro de referencia de las estrategias urbanísticas del Movimiento Moderno) se encontraron reducidas en las primeras décadas de la postguerra a círculos académicos, o vinculadas a minoritarias asociaciones en la mayoría de los casos de incidencia local, o limitadas a denodadas "campañas de opinión" de algunas personalidades culturales, teñidas casi siempre de actitudes nostálgicas... y ajenas, en gran medida, a las nuevas condiciones urbanas y sociales.

Por supuesto, todos los Estados de la Europa occidental disponían, desde el XIX, de soportes administrativos para la tutela y restauración del patrimonio histórico, pero con fuertes limitaciones: en sus prioridades (arquitecturas o lugares de valores "monumentales"), en sus capacidades inversoras y en su propia "situación" en las maquinarias estatales, al encuadrarse en los ministerios encargados de la "instrucción pública" o la "cultura", sin conexión alguna con los departamentos de gran carga económica y protagonismo político, responsables de la vivienda, las obras públicas y los equipamientos, centrados en los nuevos crecimientos. Por ello, sus atenciones hacia los cascos antiguos sólo llegaron a manifestarse en normas de "conservación pasiva", a través de la declaración de conjuntos histórico-artísticos -por emplear la terminología italiana y española- que implicaban muy esquemáticos procedimientos de tutela (aunque con algunas exploraciones de políticas activas, como las impulsadas en los 1960 por la Ley Malraux en Francia).

\section{2.}

¿Cuáles fueron los procesos que trasmutaron en todos los países europeos occidentales esos anquilosados e inoperativos marcos, dando lugar a la nueva política y cultura y política de la recuperación? De un modo muy sintético, diríamos que consistieron en "integraciones sinérgicas" de argumentaciones culturales, urbanas, sociales, económicas, que muy pronto se coagularon en potentes decisiones políticas: en la planificación urbanística, en el establecimiento de nuevos marcos legislativos y amplios recursos financieros públicos, en la disposición de estructuras específicas de gestión... En los aspectos relacionados con la cultura urbanística y arquitectónica deberíamos destacar las sustanciales "ampliaciones de campo" desarrolladas desde los 70, que se expresarían, por ejemplo, en la superación de las anteriores visiones 
sobre los tejidos antiguos, en gran medida epidérmicas, para considerar los sustratos morfológicos y tipológicos de la ciudad; en la incorporación de atenciones a la conservación y rehabilitación de las edificaciones populares, las arquitecturas de los eclecticismos historicistas, las construcciones industriales, etc.; en la articulación con otras líneas del planeamiento y del proyecto urbano (infraestructuras, movilidad, ambiente, espacios libres...); y, en fin, en la extensión de las "escalas" de actuación, antes limitadas a los viejos cascos, para incluir en sus horizontes operativos los ensanches de mediados del XIX, las agregaciones de finales de ese siglo y de las primeras décadas del XX... En los aspectos relacionados con la sociedad y la vida urbana, las atenciones e intenciones fundamentales se centraron en la defensa de los "usos tradicionales", con especial atención a la vivienda; el compromiso social con los vecindarios, sobre todo en los barrios populares degradados; la activación funcional y la inserción de dotaciones de distintos tipos, preferentemente mediante la reutilización de edificaciones antiguas; la incentivación de las interacciones sociales, confiando sobre todo en la cualificación de los espacios libres públicos...todo ello con propósitos estratégicos de valorización de los significados de los centros antiguos como lugares decisivos en la imagen y la identidad de la ciudad. Deberíamos añadir además, por sus relaciones con la actual situación de crisis, que todos esos entramados propositivos se reforzaron además con razonamientos de índole políticoeconómica, defendiendo la "reutilización" frente al "despilfarro inmobiliario" de las renovaciones y los crecimientos indiscriminados.

Esas magmáticas argumentaciones se condensaron, con mayor o menor acierto y capacidad operativa, en una reformulación, a lo largo de los 1970, de las políticas urbanas en todos los países cercanos. Nuestro país se incorporó a esa estrategia con cierto retraso, por sus circunstancias políticas, pero con un fuerte ímpetu, en coherente respuesta a las dimensiones de los problemas heredados del franquismo, con el acrecentamiento del deterioro y de la decadencia social de los antiguos cascos desde los 50 y los brutales procesos de depredación especulativa de los 1960 y 1970. En la compleja y veloz configuración de esas nuevas políticas tendrían fundamental importancia los episodios siguientes: el establecimiento, desde los primeros pasos de los Ayuntamientos democráticos en 1979, de nuevos planes, generales y especiales, que constituirían las indispensables urdimbres de esas estrategias; la creación, en 1983 , de amplios y adecuados marcos y medios de financiación pública con el $R D L$ sobre Rehabilitación del Patrimonio Residencial y Urbano, cuyos mecanismos se han mantenido básicamente hasta hoy en los sucesivos planes estatales y de las CCAA, con los procedimientos de ágiles correcciones y adiciones que proporcionaba su estructuración; los desarrollos operativos de los previsiones de los planes, apoyados en la disponibilidad de préstamos cualificados y significativas subvenciones para la "rehabilitación dispersa" y, con incidencia aún más considerable, para programas especiales de "rehabilitación integrada"; la simultánea disposición de estructuras de gestión (con los modelos de agencias especializadas de las experiencias francesas o británicas, a las que se incorporaron mecanismos de activa participación vecinal); y, en fin, la articulación con otras políticas sectoriales, integrando actuaciones sobre infraestructuras urbanas y espacios libres públicos, promoviendo la rehabilitación de edificaciones antiguas, y en algunos casos nuevas arquitecturas, para la implantación de dotaciones sociales y culturales o sedes administrativas, aprovechando dinámicamente las capacidades de las CCAA... 


\section{3.}

Unos sucintos comentarios sobre los resultados de los procesos y las nuevas tareas

- Los procesos de rehabilitación de los centros históricos, desarrollados en nuestro país desde los primeros 1980, constituyen, sin duda, una de las experiencias más valiosas de la urbanística europea en ese amplio arco temporal: por su generalizada difusión, desde las ciudades singulares a los cascos "menores"; por la articulación de estrategias de revitalización residencial y de valorización funcional y simbólica; por la variedad y aportaciones innovadoras de la proyectualidad arquitectónica desplegada en las muy numerosas actuaciones públicas "focalizadoras"... Teniendo en cuenta además que la evaluación de esos resultados se acrecienta si se consideran las lamentables condiciones de partida, cuando esos denominados "centros" eran en gran medida lugares marginales.

- En toda la exposición hemos ido apuntando la incidencia de "cuestiones políticas", pero sin precisarlas en detalle, relegándolas a connotaciones de lectura. Pero quizá para concluir sería útil algún comentario. La conformación de la cultura y de la política de rehabilitación tuvo en España una inequívoca caracterización "de izquierda" (como también en Italia, pero no en Francia ni en el Reino Unido y otros países del entorno, donde se situó en esferas con más difusos contornos... probablemente de modo más congruente con la complejidad y diversidad de los problemas). Las motivaciones de ese sesgo político e ideológico en nuestro país son fáciles de explicar: bastaría un esquemático diagnóstico DAFO sobre las condiciones que tuvieron que afrontar los gobiernos de los primeros 1980. Pero lo importante, en estos comentarios, es que esos planteamientos pronto se extenderían a otras orientaciones políticas, en un proceso que muy bien caracterizó Gramsci: la progresiva trasmutación de una ideología "de parte" en sentido común difundido en el conjunto de la sociedad...

- Para terminar: en ese desarrollo globalmente positivo de las políticas de rehabilitación ya habían comenzado a manifestarse ciertas incoherencias desde comienzos de siglo, relacionadas con el "enquistamiento" de antiguos problemas junto a la emergencia de nuevas cuestiones, pero que apenas tuvieron reconocimiento en los poderes públicos, en la exuberancia de los años de la "burbuja". El desencadenamiento de la crisis, que entre otras muchas consecuencias ha supuesto la inevitable reducción de las políticas de gasto público, exige por ello nuevas atenciones y proposiciones, en el horizonte general de una redefinición de los modelos económicos y sociales de nuestro país. En esta perspectiva, no son escasas ni fáciles, pero sí extremadamente estimulantes, las tareas que debemos afrontar los profesionales, los investigadores, los colectivos culturales y sociales, los organismos públicos, las instituciones universitarias... En lo que nos concierne como profesionales, porque en mi opinión parte importante de los nuevos planteamientos sobre los centros de nuestras ciudades deberá asentarse en "inteligencias proyectuales"... por supuesto en el planeamiento, pero también -y quizá sobre todoen la programación y la gestión urbana, económica y social. 